\title{
OBRA LITERÁRIA CHUVA BRANCA E COMUNIDADE DO TREME: UMA BREVE REFLEXÃO ACERCA DAS EXPRESSÕES IDIOMÁTICAS UTILIZADAS NESSES ESPAÇOS
}

\author{
Livia Regina Fernandes Souza (UFPA/ CAPES) ${ }^{1}$ \\ Tabita Fernandes da Silva (UFPA) ${ }^{2}$
}

\begin{abstract}
RESUMO
As expressões idiomáticas se fazem presentes quando termos ou frases assumem um significado diferente de quando são analisados por uma perspectiva isolada, isto é, a interpretação é captada de forma global pela soma das palavras. Devido a estas características, o estudo desses elementos linguísticos se torna cada vez mais difícil, uma vez que a língua possui suas variações e especificidades. Considerando que a obra Chuva Branca (1968) é caracterizada por sua grande abordagem lexical, assim como a comunidade do Treme em Bragança/Pará, este trabalho promoverá uma reflexão acerca dos fatores que contribuem para que algumas expressões idiomáticas estejam presentes nos espaços supracitados, ainda que o tempo e a realidade sejam distintas. É de grande valia ressaltar que este artigo faz parte de uma pesquisa maior que está sendo desenvolvida por meio de uma análise minuciosa e sistematizada dos principais aspectos lexicais da obra e da comunidade, tendo como base a lexicologia e a tradução cultural. Assim, este trabalho destacará pontos relevantes acerca do território amazonense, dando ênfase à cultura e aos hábitos populacionais que influenciaram e influenciam consideravelmente os aspectos linguísticos de um povo, nesse caso, os ribeirinhos.
\end{abstract}

Palavras-chave: Expressões Idiomáticas. Obra. Comunidade.

\begin{abstract}
Idiomatic expressions occur when terms or phrases take on a different meaning than when they are analyzed from an isolated perspective, that is, the interpretation is captured globally by the sum of the words. Due to these characteristics, the study of these linguistic elements becomes increasingly difficult, as the language has its variations and specificities. Considering that Chuva Branca (1968) is characterized by its great lexical approach, as well as the community of Treme in Bragança / Pará, this work will provide a reflection about the factors that contribute to some Idiomatic expressions being present in the aforementioned spaces, athough the time and reality are distinct. It is important to mention that this article is part of a larger research that is being developed through a systematized analysis of the main lexical aspects of the book and the community, based on lexicology and cultural translation. Thus, this work will emphasize relevant points about the Amazonian territory, its culture and population habits, that have considerable influence in the linguistic aspects of a people, in this case, the riverside.
\end{abstract}

Keywords: Idiomatic Expressions. Book. Community.

\section{INTRODUÇÃO}

\footnotetext{
${ }^{1}$ Graduada em Letras- Língua Inglesa pela Universidade Federal do Pará (UFPA), graduada em Pedagogia pela Faculdade Pan Americana (FPA). Especialista em Tradução, Leitura e Compreensão de Textos de Especialidade em Língua Estrangeira- Universidade Federal do Pará (UFPA). Cursando pós-graduação (Mestrado) em Linguagens e Saberes na Amazônia (PPLSA) - Universidade Federal do Pará (UFPA) - Campus de BragançaPA. E-mail: liiviinha2009@yahoo.com.br.

${ }^{2}$ Graduada em Licenciatura Plena em Letras pela Universidade Federal do Pará (1992). Mestre em Letras (Linguística) pela Universidade Federal do Pará (2001). Doutora em Linguística pela Universidade de Brasília (2010). E-mail: tabitafs1@hotmail.com.
} 
Este trabalho busca apresentar uma reflexão acerca dos fatores que influenciaram e influenciam a utilização de algumas expressões idiomáticas no romance regionalista do autor Paulo Jacob, a obra Chuva Branca (1968), e no dialeto dos moradores da Comunidade do Treme, uma localidade bem distante em comparação ao espaço e ao tempo apresentados no livro. Considerando que o cenário no qual se passa a aventura narrada é o espaço ribeirinho do estado do Amazonas, que retrata a história de vida de um homem do interior e suas aventuras quixotescas perdido na selva, a variedade de linguagem usada na escrita da obra é marcadamente representativa deste espaço. Como o emprego da linguagem acontece em um continuum, escolhemos como questão básica para a pesquisa a seguinte: O que leva algumas expressões idiomáticas utilizadas na obra Chuva Branca (1968), a serem conhecidas e empregadas atualmente em outros espaços da região amazônica? A partir deste questionamento, propusemo-nos a iniciar uma observação, que ainda está em andamento, de uma comunidade de pescadores da região de Bragança, a Comunidade do Treme, com foco no conhecimento e uso de expressões idiomáticas registradas a partir do romance Chuva Branca. Este artigo está fundamentado nos princípios das ciências do léxico e, por ainda estar em fase de desenvolvimento, lança mão especialmente de pesquisas bibliográficas.

O estudo das Expressões Idiomáticas (EI) consiste em um campo de grande importância por ser um recurso de linguagem utilizado em várias situações por falantes de diferentes línguas. Embora o propósito de nossa pesquisa seja o de analisar algumas expressões idiomáticas presentes na obra Chuva Branca (1968) em comparação com o léxico dos moradores da comunidade do Treme, levando em consideração o espaço, o tempo e a realidade social por elas apresentadas, ainda não o faremos no presente estudo. Neste nos limitaremos a prover algumas reflexões em torno dos fatores que contribuíram e contribuem para que as mesmas expressões, aparentemente tão demarcadas espacialmente, sejam empregadas em tempo e espaço distintos. Vale ressaltar que as EI não se classificam como um conjunto de idiossincrasias lexicais, mas como combinações convencionais regulares de relações sintático-semânticas e pragmáticas dentro de uma irregularidade (CORBIN, 1983; TAGNIN, 1988).

Identificar o porquê da permanência com relação ao uso de alguns aspectos linguísticos considerando principalmente o papel da cultura sobre a língua e o sentido por trás das palavras, será um dos pontos-chave deste trabalho. Com isso, este artigo terá como foco de reflexão as expressões idiomáticas utilizadas na obra e na comunidade, tendo como fundamento estudos da área da lexicologia e da tradução cultural como forma de facilitar e 
complementar os aspectos históricos e sociológicos que aqui serão discutidos. Por fim, este trabalho também fará uso de ideias propostas por alguns estudiosos e pesquisadores, principalmente os que estão voltados à área da literatura romântica, no intuito de aprimorar e reforçar as ideias aqui apresentadas.

\section{A AMAZÔNIA EM CHUVA BRANCA}

Na década de 60, especificamente no ano de 1968, o autor Paulo Jacob, romancista renomado com relação a escrituras sobre o território amazônico, publicou uma de suas principais obras, o livro Chuva Branca. Marcado por traços regionalistas, a arte aqui enfatizada tem como intuito denunciar os descasos sociais que atingem a realidade dos ribeirinhos amazônidas. Uma floresta desamparada, ameaçada pelos interesses políticos e nem um pouco valorizada, é mostrada ao longo da narrativa. Jacob expõe nos capítulos de Chuva Branca o lado positivo e o lado negativo da Amazônia, o que faz do romance uma das principais obras referentes a nossa região.

Buscando enfatizar todas as informações citadas anteriormente, este capítulo estará voltado para a história da Amazônia nos anos 60, trazendo todas as informações possíveis relacionadas ao autor Paulo Jacob e seu romance Chuva Branca. Vale ressaltar que o tópico referente à obra terá como foco três elementos específicos da narrativa: o homem, o espaço e as adversidades; sendo estes a base para a construção dos dados desta pesquisa.

\subsection{A AMAZÔNIA DE 1960: UMA NOVA HISTÓRIA}

Há mais de 18 mil anos deu-se início a história de ocupação da Amazônia pelos imigrantes asiáticos, todavia, especificamente no século 19, depois de idas e vindas de colonizadores, o território estava completamente dominado pela miscigenação, onde brancos, índios e negros trabalhavam assiduamente em torno do ciclo econômico da borracha. Tal ciclo favoreceu o crescimento financeiro dos mercados, em especial os que pertenciam aos nobres de Manaus e Belém.

Depois de um alto índice de exportação e crescimento econômico, já na primeira metade do século 20, o ciclo da borracha entrou em declínio, causando o esquecimento da grande Amazônia. Então, após alguns anos de estagnação, já em 1960, o Governo Federal passou a investir em planos de integração nacional, através da criação de novos projetos e incentivos fiscais que contribuíram significativamente para que a região voltasse a ser alvo e passasse a receber constantemente novos migrantes. Tais mudanças acarretam uma série de 
consequências, principalmente no que se refere à paisagem do território, que precisou ser devastada após iniciarem a construção de estradas que tinham como principal objetivo facilitar o processo de exploração, uma vez que até então a dinâmica de circulação era feita, em maior parte, através dos rios. Nesse período deram início à construção da BR-010, que liga Belém a Brasília, e da BR- 364, que liga Cuiabá a Rio Branco.

\begin{abstract}
A BR-010 (Belém-Brasília) foi a propulsora da agricultura, da pecuária, e do consequente aumento da população da Amazônia a partir da década de 1960. Essa rodovia reduziu o custo para o estabelecimento de migrantes, facilitou viagens para o resto do país e tornou o transporte dos produtos agrícolas mais baratos. A BR-364 (Cuiabá-Rio Branco) desencadeou a maior migração para territórios virgens da história da América do Sul. Até a década de 1980, 500 mil colonos, principalmente agricultores do Sul do país, haviam se deslocado pela BR-364; e essa migração foi acelerada na década seguinte. Após sua pavimentação, uma rede de estradas de corta a floresta em ambos os lados da rodovia foi estabelecida. Essas estradas promoveram a intensificação de atividades agropecuárias, a exploração mineral (cassiterita) e o estabelecimento de muitos aglomerados populacionais. (IMAZON, 2015)
\end{abstract}

Ainda em 1960, a Amazônia dá um salto em sua história, agora por meio da criação de projetos econômicos, incentivo à agropecuária e descoberta de novos minérios. O processo de industrialização e a consequente modernidade são os principais pontos de contribuição para essa "nova" realidade. A partir dessas políticas de desenvolvimento foram surgindo diversos acontecimentos, entre eles o crescimento urbano, o crescimento populacional devido à chegada dos migrantes, os impactos ambientais e sociais, e o avanço na intensidade dos conflitos. Tais mudanças influenciaram e influenciam grandemente, principalmente com relação à criação de metrópoles, cidades pequenas, médias e cidades planejadas. Vale ressaltar que, de início, a ocupação das áreas florestais se restringia às margens das estradas, evoluindo somente a partir da década de 70 .

É importante enfatizar que em 1964 o Brasil vivenciava o período da ditatura, onde os militares consideravam de extrema importância a unificação do país e a proteção da floresta amazônica no que se refere à internacionalização, isto é, a troca de benefícios políticos, econômicos e culturais entre nações, e suas devidas consequências. Segundo Peixoto (2009), dois anos depois, no ano de 1966, o presidente Castelo Branco se manifesta e passa a trabalhar em cima do lema "Integrar para não Entregar". Contudo, apesar de contraditório, os benefícios advindos da Amazônia favoreciam em maior parte a classe alta, e ainda que a região estivesse recebendo uma inúmera quantidade de migrantes, a maioria das terras pertenciam exclusivamente à União e ao Estado. (PEIXOTO, 2009) 
$\mathrm{Na}$ década de 60, o marco do desenvolvimento da região Amazônica estava ligado à criação e aprimoramento da Zona Franca de Manaus (ZFM). De acordo com Schontag (2015, p.1), a ZFM "foi criada em 1967 com o objetivo de promover o desenvolvimento socioeconômico da Região Amazônica" e tem os polos comerciais voltados para as áreas industriais, comerciais e agropecuárias. Diante de tantos avanços, a disseminação de políticas públicas que buscavam benefícios próprios e o desenvolvimento de projetos que visavam mudanças convenientes aos grupos de poder cresceram de forma alarmante, prejudicando a classe menos favorecida. Assim, o ano de 1960 foi o propulsor do reestabelecimento e consequente crescimento da Amazônia que vemos em pleno século 21, que mesmo acarretando diversas consequências de âmbito negativo, como o desmatamento, é fundamental para a vida social e econômica não só do Brasil, mas também de muitos outros países.

\section{UMA BREVE INTRODUÇÃO À OBRA CHUVA BRANCA}

Paulo Jacob escreveu o livro Chuva Branca como uma forma de manifestar sua indignação relacionada à dura realidade vivenciada pelos ribeirinhos. A mata é o local que norteia todos os acontecimentos e serve como "moradia" para o protagonista da "história", que narra todo seu sofrimento, chamando atenção ao descaso alarmante sofrido pela sociedade. $\mathrm{O}$ texto encontra-se dividido em dois momentos: o primeiro, que leva o nome da obra Chuva Branca, umas das principais adversidades enfrentadas por Luís Chato; e o segundo, que é denominado de mãe do rio, local no qual o ribeirinho tinha anseio em encontrar, uma vez que servia como indicação do seu caminho de volta para casa.

A obra é composta por 229 páginas narradas de forma magnífica pelo próprio personagem. Os capítulos relatam a vida de um homem sábio, orgulhoso e conhecedor da mata, que acaba se perdendo dentro de seu "próprio território". A narrativa é repleta de histórias e superstições que rodeiam o território amazonense. Os mitos, entre eles o do curupira, mapinguari, e mãe-do-rio, também fazem parte do dia a dia do Luís Chato e estão presentes no intuito de mostrar a ele o valor e a importância dos saberes interioranos nos acontecimentos do dia a dia.

Os acontecimentos no decorrer da narrativa são detalhados minuciosamente, o que motiva o leitor a ter que se atentar aos detalhes, sem que possa se aprofundar na imaginação. “A Literatura, como toda arte, é uma transfiguração do real, é a realidade recriada através do espírito do artista e retransmitida através da língua para as formas, que são os gêneros, e com os quais ela toma corpo e nova realidade" (COUTINHO 1978, p.9-10). Dessa forma, o livro 
Chuva Branca busca mostrar claramente em sua história, traços da desigualdade vivenciada pelo homem amazônida. Toda a narrativa é acompanhada de uma rica linguagem, cheia de expressões e etnotermos, que fazem da obra uma riqueza literária.

\section{EXPRESSÃO IDIOMÁTICA E SUAS DEFINIÇÕES}

São diversas as nomenclaturas que definem o que é "Expressão Idiomática" (EI), entre elas podemos citar: fraseologismo, expressão cristalizada, idiomatismo, frase idiomática, entre outras. Todavia, como as EI nem sempre se apresentam de forma clara dentro de um discurso, a sua delimitação não se torna uma tarefa fácil. Segundo Xatara (1998, p. 149), “expressão idiomática é uma lexia complexa indecomponível, conotativa e cristalizada em um idioma pela tradição cultural". As EI não se delimitam a uma unidade linguística, pois seguem os mesmos princípios morfológicos do fonema (unidade da fonologia), grafema (escrita), morfema (morfologia), lexema (lexicologia) e semantema (semântica).

As expressões idiomáticas podem ser caracterizadas por três atributos: indecomponibilidade, convencionalidade e conotatividade. $\mathrm{O}$ aspecto indecomponível está no fato de que uma EI é formada por um sintagma fixo e qualquer alteração em sua estrutura acarreta mudança de sentido. O aspecto convencional, como o próprio nome já diz, caracteriza-se por ser de consenso de uma comunidade, isto é, as unidades (poli)lexicais ${ }^{3}$ precisam ser utilizadas dentro de uma sociedade para que possam se constituir como unidades lexicalizadas, o que nos mostra a necessidade que as expressões têm de se tornarem estáveis ao logo do tempo. Assim, a frequência com que determinadas palavras ou frases são utilizadas dentro de uma comunidade de falantes, possibilita a cristalização de sua tradição linguística cultural.

Por outro lado, o aspecto conotativo refere-se ao sentido figurado e metaforizado das expressões idiomáticas. São elementos que possuem como intuito atender aos desejos comunicativos dos falantes, pois embora a língua disponha de meios que podem suprir essas necessidades, a busca por um diálogo mais expressivo e persuasivo é constante. Cunha e Ferraz (2010, p. 72), ao falarem sobre conotação, fazem a seguinte afirmação: "quanto à interpretação semântica de uma unidade, esta não pode ser calculada a partir da soma de seus elementos constituintes e, por isso mesmo, uma EI será sempre conotativa”, o que demonstra a necessidade que os indivíduos têm de analisar determinadas frases como um todo, sem se

\footnotetext{
${ }^{3}$ Ferraz (2010, p. 38-39) as define como "unidades constituídas de mais de uma palavra, com certa coesão interna entre os seus componentes, tornando-se combinações fixas que, no sistema e na frase, podem assumir a função e o significado de palavras individuais".
} 
prender a um único ambiente. Dessa forma, podemos observar em Chuva Branca uma de suas principais características, a presença constante de expressões idiomáticas um tanto quanto desafiadoras, uma vez que são diversas as possibilidades de interpretação.

\section{A OBRA CHUVA BRANCA E A COMUNIDADE DO TREME: LÍNGUA E CULTURA ENTRELAÇADAS À REVELIA DO TEMPO E DO ESPAÇO}

Bruno Latour (2004) em seus questionamentos reflete acerca das barreiras presentes entre a ideia de fenômenos naturais no âmbito científico; e as ações da vida social, a cargo da política. Os dois campos, aparentemente distintos, travam uma relação involuntária entre si, quando nos voltamos à análise da sociedade e seus estereótipos culturais. A implicação dessa visão bifocal abre caminhos para múltiplos questionamentos sobre natureza e natureza humana (HARVEY, 2003), que quando observadas de forma minuciosa, constroem opiniões não necessariamente antagônicas.

Considerando a ideia de que a natureza humana é a soma do comportamento e das experiências vivenciadas pela espécie humana (CERQUEIRA, 2006), é importante enfatizar que as concepções que atuam em conjunto com os objetivos e princípios de ideias de um processo social evolutivo frisam a diferença entre a capacidade do homem de transformar a natureza e de mudar sua própria natureza. Partindo dessa perspectiva, podemos citar as questões linguísticas apresentadas na obra Chuva Branca de Paulo Jacob e no dialeto dos moradores da comunidade do Treme, que por vivenciarem a cultura ribeirinha, mesmo que em época e em espaços distintos, possuem características marcantes, que nos levam a refletir acerca das "modificações" que a língua sofreu com o passar dos tempos devido a influências internas ou externas, as quais podemos denominar de hibridização linguística ${ }^{4}$ ou mistura das línguas (BURKE, 2003). "Linguística trata-se do estudo de como os membros de uma comunidade se comunicam entre si, tanto oral como gestualmente" (COUTO, 2009, p.15).

Analisar as questões linguísticas que norteiam a obra Chuva Branca, possibilita entender o papel social e cultural das comunidades, uma vez que "a linguagem é um código que caracteriza o sistema de comunicação" (LAUFER \& LECHERBONNIER,1975, p. 4). Dessa forma, para que possamos realizar este estudo é fundamental considerarmos o espaço onde ocorre a ação, uma vez que o determinismo geográfico entende que as diferenças presentes em um ambiente físico condicionam amplamente a diversidade cultural e, consequentemente, linguística (LARAIA, 1986).

\footnotetext{
${ }^{4} \mathrm{O}$ hibridismo linguístico caracteriza-se pela formação de palavras com elementos oriundos de outras línguas ou culturas (BURKE, 2003).
} 
"Todas as culturas estão envolvidas entre si", escreve Said a respeito de nossa situação atual; "nenhuma delas é única e pura, todas são híbridas, heterogêneas" (BURKE, 2003, p. 53). Ainda diante dessa afirmação, os diferentes tipos de campos (locais), alvos dessa pesquisa, são dominados pela lógica de existência e valor, onde cada um determina para si o que é importante ser adquirido, ou seja, dependendo do meio são diferentes as necessidades encontradas. Tal fato pode ser concretizado ao percebermos que, em algumas comunidades ribeirinhas a língua usada se limita a um meio de comunicação puramente eficaz, sem que haja outros interesses.

Ainda considerando as diferenças e a ideia de que a cultura é um fenômeno natural que possui causas e regularidades sobre a evolução (LARAIA, 1986), podemos dar maior ênfase às expressões idiomáticas presentes na obra e no léxico da comunidade, em que pesquisas geraram reflexões acerca de seus significados e modificações no tempo e espaço local, já que de 1968, ano em que obra foi escrita, até 2018, muitas foram as alterações na língua. "A linguagem humana, por outro lado, é um sistema aberto, um sistema que é capaz de produzir um número quase infinito de enunciados, alguns aprendidos, mas muitos outros formados com base em padrões comuns à comunidade linguística" (HILL, 1902, p. 56).

São diversos os conjuntos de palavras responsáveis por apresentar um mesmo significado, principalmente se os analisarmos de forma abrangente. Os diversos hábitos culturais, religiosos, políticos e artísticos vividos por um povo em um dado território influenciaram significativamente e acabaram por deixar na língua marcas que acentuam a riqueza do vocabulário e da pronúncia. Por conseguinte, a influência de elementos específicos de determinadas regiões do país aliada ao desenvolvimento histórico, faz com que surjam regionalismos, principalmente no que se refere a expressões idiomáticas. Segundo Burke (2003, p. 44), tal acontecimento pode ser denominado de empréstimo cultural ou troca cultural, uma vez que "a história de todas as culturas é a história do empréstimo cultural".

\subsection{A LÍNGUA A PARTIR DAS RELAÇÕES HÍBRIDAS}

Uma boa relação não pode ser vista dentro da matéria, da forma, ou até mesmo nas substâncias e atributos, mas sim entre materiais e forças, que dependem claramente de como diferentes indivíduos são influenciados a partir de pensamentos e estereótipos construídos e fundidos uns aos outros no decorrer do tempo (Deleuze \& Guattari, 2004). Considerando que a sociedade possui suas interfaces, esta afirmação contribui para que possamos refletir acerca das variações linguísticas oriundas de relações híbridas, uma vez que a língua está em 
constante processo de transformação. A obra Chuva Branca proporciona essa visão, ao mostrar por meio de seu vocabulário que as diferenças no modo de se comunicar, podem ou não receber influência de aspectos locais. "Amselle, especialista em África Ocidental, defende que não existe uma fronteira cultural nítida ou firme entre grupos, e sim, pelo contrário, um continuum cultural. " (BURKE, 2003, p. 14)

Dessa forma, podemos observar que a língua passa a ser entendida como ferramenta de comunicação de um significado e de uma verdade até então estável, que pode ou não ser transferida integralmente entre sistemas linguísticos-culturais. Alguns desses aspectos durante a comunicação são transmitidos por gerações, fazendo-se necessário que o ouvinte e pesquisador tenham noção dessas "heranças culturais", respeitando e compreendendo as particularidades de cada indivíduo, para que assim a " mensagem" durante um determinado diálogo seja recebida e compreendida da melhor maneira.

“O preço da hibridização, especialmente naquela forma inusitadamente rápida que é característica de nossa época, inclui a perda de tradições regionais e de raízes locais. " (BURKE, 2003, p.18). Assim, quando nos voltamos à obra podemos perceber o quanto é importante o conhecimento cultural e principalmente linguístico dos ribeirinhos no século XX, uma vez que o livro é formado por um vocabulário que dificilmente é utilizado nos dias atuais. Um olhar mais atento a esses aspectos que contribuem para o engrandecimento do texto nos faz perceber que quanto mais a pesquisa e os projetos (que atuem dentro desse contexto) se voltarem para a história da linguagem e das comunidades de forma simultânea e considerando suas especificidades individuais, maior será o desenvolvimento e a qualidade dos estudos.

\footnotetext{
A língua se forma e se transforma, ou seja, nasce, vive e definha em função dos atos de interação comunicativa, ou da ausência deles. Dito de outro modo, por um lado, ela só pode nascer na interação, ou seja, das pessoas tentando se comunicar. Por outro lado, nos próprios atos de interação comunicativa concretos, a língua se altera para se adaptar a novas situações. (COUTO, 2009, p. 45)
}

A construção da relação com o outro, quando analisada de um campo epistemológico, como afirma Ingold (2012), precisa estar entrelaçada diretamente aos fins ou objetivos de uma determinada matéria, ou seja, a idealização do que se pretende obter a partir de uma relação específica, necessita antes ser pré-estabelecida para que haja consonância entre os objetos de estudos. Por essa razão, muitas vezes encontramos textos, artigos e até mesmo livros que possuem sentido equivocado ou contrário à realidade, o que nos leva a refletir acerca da importância de se ter uma pesquisa bem organizada desde a sua idealização. 
A compreensão com relação às variações sociolinguísticas nos possibilitam uma considerável ampliação da comunicação, principalmente no que se refere ao "discurso", que segundo Fairclough (2001, p. 91) trata-se de “ um modo de ação, uma forma em que as pessoas podem agir sobre o mundo e especialmente sobre os outros, como também um modo de representação". Diante de tantas teorias, podemos perceber que a sociedade precisa conhecer e respeitar a identidade do outro, não só para obter conhecimento, mas também para compreender a própria identidade, uma vez que é de grande importância preservar as tradições daqueles que contribuíram e contribuem para construção social. " $\mathrm{O}$ valor de uma língua não depende do número de falantes nem de seu poder socioeconômico. Toda língua veicula uma visão de mundo, uma tecnologia única, que desapareceriam com ela. " (COUTO, 2009, p. 22)

Feenberg (2003) ao abordar algumas teorias com relação à cultura social, afirma que o modo de pensar de cada pessoa está relacionado a costumes e mitos que não podem ser explicados facilmente, o que induz à proibição de algumas perguntas e ideologias que venham a ser contrárias ao sistema de crenças. Todavia, ainda que os costumes linguísticos em alguns casos necessitem se justificar, mesmo que de forma indireta, como sendo úteis para a sociedade, a modernidade oprime o poder de discutir sobre as formas tradicionais de pensamento. Diante de tantas situações, as pesquisas em colaboração com a ciência e a tecnologia passaram a atuar ativamente, influenciando e proporcionando meios para a formação de novos pensamentos.

Na verdade, a língua não se transmite; ela dura e perdura sob a forma de um
processo evolutivo contínuo. Os indivíduos não recebem a língua pronta para ser
usada; eles penetram na corrente da comunicação verbal, ou melhor, somente
quando mergulham nessa corrente é que sua consciência desperta e começa a operar.
É apenas no processo de aquisição de uma língua estrangeira que a consciência já
constituída - graças à língua materna - se confronta com uma língua toda pronta,
que só lhe resta assimilar. Os sujeitos não "adquirem" sua língua materna, é nela e
por meio dela que ocorre o primeiro despertar da consciência. (BAKHTIN,1997, p.
108)

Dessa forma, é de suma importância que ao analisar a obra literária Chuva Branca e a comunidade do Treme, os aspectos e as especificidades linguísticas sejam levados em consideração. Contudo, ainda que essa ideia esteja em uma condição sine qua non ${ }^{5}$ para a compreensão lexical dos objetos de pesquisa, é fundamental considerarmos outras características, principalmente no que se refere à cultura social e ao ano de análise, uma vez que é indispensável que o conhecimento do leitor e os aspectos da obra caminhem lado a lado para que a compreensão textual e a pesquisa sejam melhores desenvolvidas.

\footnotetext{
${ }^{5}$ Refere-se a uma ação cuja condição ou ingrediente é indispensável e essencial.
} 


\section{CONSIDERAÇÕES FINAIS}

A obra Chuva Branca e a comunidade do Treme, objetos de análise dessa discussão, apresentam caraterísticas similares quanto ao uso do léxico, principalmente no que se refere à expressões idiomáticas. Por esse trabalho se inserir em uma pesquisa maior, esta análise ainda não foi completamente aprofundada, mas nossas observações assistemáticas indicam essa similaridade.

Embora o tempo e o espaço entre a escrita da obra e a análise da comunidade sejam distintos, a recorrência de determinadas expressões idiomáticas são claramente perceptíveis, e ainda que não haja uma relação significativa entre o espaço mostrado na obra Chuva Branca e o momento vivenciado pela comunidade do Treme, salvo o fato de que esta é uma comunidade ribeirinha que sobrevive dos frutos do mar, a pouca similaridade que há entre os objetos de pesquisa é um forte indicador do caráter migratório das expressões da língua e das importantes trocas culturais que marcam as relações entre os homens.

A partir dessa perspectiva algumas questões ainda serão investigadas, entre elas a seguinte: até que ponto as expressões idiomáticas presentes na obra e na comunidade do Treme ainda guardam os mesmos significados?

\section{REFERÊNCIAS}

BAKHTIN, Mikhail. Marxismo e filosofia da linguagem. 8. ed. São Paulo: Hucitec, 1997.

BARKER, K.; BURDICK, D. Bíblia de Estudo NVI. São Paulo: Editora Vida, 2003.

BENCHIMOL, Samuel. Amazônia: Formação Social e Cultural. Manaus: Editora Valer, 1999.

BERGER, Peter L. LUCKMANN, Thomas. A construção social da realidade: tratado de sociologia do conhecimento. Tradução de Floriano de Souza Fernandes. Petrópolis: Editora Vozes-1966.

BERGER, Peter L. LUCKMANN, Thomas. Hibridismo Cultural. Editora UNISINOS- São Leopoldo (RS), 2003.

BIDERMAN, Maria Tereza Camargo. A estrutura mental do Léxico. In: QUEIROZ, T. A (Ed.) Estudos de filologia e linguística: em homenagem a Isaac Nicolau Salum. São Paulo: Editora da Universidade de São Paulo, 1981.p. 131 - 145. 
BIDERMAN, Maria Tereza Camargo. As Ciências do Léxico. In: OLIVEIRA, Ana Maria Pires de \& ISQUERDO, Aparecida Negri (Org.). As Ciências do Léxico: lexicologia, lexicografia, terminologia - 2 ed. - Campo Grande, MS: ed. UFMS, 2001, p. 13 - 22.

BRASIL. Decreto n. 6040, de 7 de fevereiro de 2007. Instituiu a Política Nacional de Desenvolvimento Sustentável dos Povos e Comunidades Tradicionais. Diário Oficial da União, 8 fev. 2007, Seção 1, p. 316.

BURKE, Peter. Hibridismo Cultural. Editora UNISINOS- São Leopoldo (RS), 2003.

CERQUEIRA, Hugo E. A da Gama. A filosofia moral de Adam Smith. In: ENCONTRO NACIONAL DE ECONOMIA ANPEC, 34, 2006. Salvador, BA. Anais eletrônicos. Salvador, BA: Anpec, 2006. Disponível em: $<$ http://www.anpec.org.br/encontro2006/artigos/A06A039.pdf $>$. Acesso em: 12 de dezembro de 2018.

CORBIN, Danielle. Le monde étrange des dictionnaires (4): la créativité lexicale, le lexicographe et le linguiste. Lexique (Paris), n.2, p.43-68, 1983.

COSERIU, Eugenio. Princípios de semántica estructural. Vers. esp. de Marcos Martinez Hernández, rev. por el autor. Madrid: Gredos, 1977.

COUTINHO, Afrânio. Notas de teoria literária. 2. Ed. Rio de Janeiro, Civilização Brasileira, 1978. p. 9-10.

COUTO. Hildo Honório do. Linguística, ecologia e ecolinguística: contato de línguas/ Hildo Honório do Couto. São Paulo: Contexto. 2009.

CUNHA, Aline Luiza da; FERRAZ, Aderlande Pereira. Expressões idiomáticas na sala de aula de língua materna: o tratamento dessas unidades lexicais no livro didático. In: ALVES, Ieda DELEUZE, Gilles; GUATTARI, Félix. Para Ler a Filosofia, 2004.

FAIRCLOUGH, Norman. Discurso e Mudança Social/ Norman Fairclough; Izabel Magalhães, coordenadora da tradução, revisão técnica e prefácio. - Brasília: Editora Universidade de Brasília, 2001, 2008 (reimpressão), 320p.

FEENBERG, Andrew. O que é Filosofia da Tecnologia? (2003). Disponível em:

http://www.sfu.ca/ andrewf/FeenbergOQueEFilosofiaDaTecnologia.pdf.Acesso em: 12 de dezembro de 2018.

GECKELER, Horst. Semântica estructural y teoria do campo léxico. Vers. esp. de Marcos Martinez Hernández. Madrid: Gredos, 1976.

GUEDELHA, C. A. M. A metaforização da Amazônia em textos de Euclides da Cunha. 2013. 317 f. Tese (Doutorado em Linguística) - Universidade Federal de Santa Catarina, Florianópolis, SC, Brasil, 2013.

HILL, Archibald Anderson. Aspectos da Linguística Moderna. Tradução: Adair Pimentel Palácio, Maria do Amparo B. de Azevedo e Maria Antonieta A. Celani, apresentação da ed. 
Brasileira por Izidoro Blikstein. $2^{\mathrm{a}}$ ed. São Paulo, Cultrix, Ed. da Universidade de São Paulo, 1974.

IMAZON. A floresta habitada: História da ocupação humana na Amazônia. 2015. Disponível em: https://imazon.org.br/a-floresta-habitada-historia-da-ocupacao-humana-naamazonia/. Acesso em: 01 de abril de 2019.

INGOLD, Tim. Trazendo as Coisas de Volta à Vida: Emaranhados Criativos num Mundo de Materiais. Horizontes Antropológicos, Porto Alegre, amo 18, n. 37, p. 25-44, jan. / jun. 2012.

JACOB, P. A noite cobria o rio caminhando. Rio de Janeiro: Nórdica, 1983.

JACOB, P. Amazonas, remansos, rebojos e banzeiros. Rio de Janeiro: Nórdica, 1995.

JACOB, P. Andirá. Manaus: Editora Sergio Cardoso, 1965.

JACOB, P. Assim contavam os velhos índios ianõnãmes. Rio de Janeiro: Nórdica, 1995.

JACOB, P. Chãos de Maíconã. Rio de Janeiro: Companhia Editora Americana, 1974.

JACOB, P. Chuva branca. Rio de Janeiro: Gráfica Record Editora, 1968.

JACOB, P. Dicionário da língua popular da Amazônia. Rio de Janeiro: Editora Cátedra, 1985.

JACOB, P. Dos ditos passados nos acercados do Cassianã. Rio de Janeiro: Bloch, 1969.

JACOB, P. Estirão e mundo. Rio de Janeiro: Nórdica, 1979.

JACOB, P. Muralha verde. Manaus: Editora Sergio Cardoso, 1964.

JACOB, P. O coração da mata, dos rios, dos igarapés e dos igapós morrendo. Rio de Janeiro: Nórdica, 1991.

JACOB, P. O gaiola tirante rumo do rio da borracha. Rio de Janeiro: Editora Cátedra, 1987.

JACOB, P. Tempos infinitos. Manaus: Editora Uirapuru, 2004.

JACOB, P. Um pedaço de lua caía na mata. Rio de Janeiro: Nórdica, 1990.

JACOB, P. Vila rica das queimadas. Rio de Janeiro: Companhia Editora Americana, 1976.

LARAIA, Roque de Barros. Cultura: um conceito antropológico. Rio de Janeiro: Zahar, 1986.

LATOUR, Bruno. Políticas da natureza: como fazer ciência na democracia. Tradução Carlos Aurélio Mota de Souza. Bauru, SP: Edusc, 2004. 
LAUFER, Roger; LECHERBONNIER, Bernard. Litterature et Langages: Les Genres et Les Themes - Le Language, Le Théâtre, Le Parole, Et L'image. Collection Dirigée Par. Éditions Fernand Nathan, 1975.

LEWIS, M. The lexical approach: The state of ELT and the way forward. Hove, England: Language Teaching Publications, 1993.

LOURO, F. L. S. A significação social na Amazônia no romance Chuva Branca de Paulo Jacob. Novum Millenium, Manaus, v. 5, p. 72-78, 2007.

Maria et al. (orgs.). Os estudos lexicais em diferentes perspectivas. vol. 2. São Paulo: FFLCH/USP, p. 70-78, 2010.

MENDONÇA, R. Memórias amazonenses (2012). Disponível em: http://catadordepapeis.blogspot.com.br/2012_02_01_archive.html. Acesso em: 15 de dezembro de 2018.

PEIXOTO, Fabrícia. Linha do tempo: Entenda como ocorreu a ocupação da Amazônia.

BBC- NEWS/ BRASIL. Brasília, 2009. Disponível em:
https://www.bbc.com/portuguese/noticias/2009/07/090722_amazonia_timeline_fbdt. Acesso em: 01 de abril de 2019.

POTTIER, Bernard; AUDUBERT, Albert; PAIS, Cidmar Teodoro. Estruturas linguísticas do português. São Paulo: Difusão Europeia do Livro, 1972.

PROENÇA FILHO, D. A linguagem literária. 8. ed. São Paulo: Ática, 2007.

RIVA, Huélinton Cassiano; CAMACHO, Beatriz Facicani. Expressão idiomática: uma unidade fraseológica. In: BARROS, Lídia Almeida; ISQUERDO, Aparecida Negri. O léxico em foco: múltiplos olhares. São Paulo: Cultura Acadêmica, 2010. p. 195-217.

SALGADO, E. Presença judaica na Amazônia: preservação e aculturação, um estudo através do caso dos Elmaleh/Salgado (2010). Disponível em: http://www.amazoniajudaica.org/167563/presença-judaica-na-amazonia preservaçao-eaculturaçao. Acesso em: 15 de dezembro de 2018.

SAMUEL, R. Paulo Jacob (2008). Disponível em: http://archive.is/yARi. Acesso em: 12 de dezembro de 2018.

SCHONTAG, José Antonio. Os incentivos fiscais da Zona Franca de Manaus: As matérias-primas regionais para produção de "concentrados". FGV Projetos Artísticos, 2015.

SOUZA, J. A.; LOURO, F. L. S. Chuva Branca: o retrato cultural da sociedade amazônica brasileira na obra de Paulo Jacob. Revista Decifrar, v. 02, p. 135-151, 2014.

TAGNIN, S. E. O. A tradução dos idiomatismos culturais. Trabalhos de Lingüística Aplicada, n.11, p.43-52, 1988. 
VILELA, Mário. Estudos de Lexicologia do Português. Coimbra: Livraria Almedina, 1994.

XATARA, Claudia Maria. O campo minado das expressões idiomáticas. Alfa. São Paulo, 42 (n. esp.), p. 147-159, 1998.

XATARA, Claudia Maria. Dicionário de expressões idiomáticas: português do Brasil e de Portugal - francês da França, da Bélgica e do Canadá. 2013. Disponível em: http://www.deipf.ibilce.unesp.br/pt/index.php. Acesso em: 12 de dezembro de 2018.

Recebido em: 09/07/2019

Aprovado em: 30/07/2019 